\title{
Cardiac effects of chronic renal failure and haemodialysis treatment Hypertensive versus normotensive patients
}

\author{
MARKKU IKÄHEIMO, KAISA HUTTUNEN, JUHA TAKKUNEN \\ From the Cardiovascular Division and Dialysis Unit, Department of Medicine, University of Oulu, \\ Finland
}

SUMMARY In order to investigate differences in cardiac changes between normotensive and hypertensive patients with chronic renal failure, and the effects of haemodialysis on cardiac function, 31 hypertensive and 10 normotensive patients with chronic renal failure and uraemia were examined by echocardiography before and after a total of 69 haemodialyses.

There were no differences between the groups with regard to left ventricular end-diastolic size and function. In hypertensive patients the left ventricular masses and posterior wall thicknesses were greater than in normotensive patients in response to chronically increased left ventricular afterload. In 29 per cent of hypertensive patients the ratio of interventricular septal to posterior wall thickness was abnormal. The left atrial diameter was also greater in the hypertensive group as a response to decreased left ventricular compliance.

In all the patients haemodialysis caused a significant decrease in body weight and diastolic blood pressure. The left atrial diameter and left ventricular end-diastolic diameter decreased obviously as a response to decreased ventricular filling pressure because of decreased blood volume, but the cardiac index did not decrease significantly. The differences in cardiac changes caused by haemodialysis between hypertensive and normotensive patients were very small: the left atrial diameter decreased significantly only in hypertensive patients and heart rate increased only in normotensive patients.

Hence, in chronic renal failure, left ventricular hypertrophy is principally caused by arterial hypertension and left ventricular dilatation by factors such as increased blood volume and cardiac output. Haemodialysis principally causes a decrease in left ventricular diastolic volume and less decrease in cardiac output. Hypertensive and normotensive patients seem to be similarly susceptible to the haemodynamic effects of haemodialysis.

In chronic renal failure the heart and circulation are affected by several pathological mechanisms. Cardiac output is increased because of the increased oxygen demand of the tissues, because of chronic anaemia, and chronic volume overload. ${ }^{1}$ An arteriovenous fistula for haemodialysis treatment also augments cardiac output, decreasing the peripheral vascular resistance. ${ }^{1-5}$ Arterial hypertension also causes cardiac changes, which are the most important factors affecting the patients' prognosis. ${ }^{6}$ Uraemic changes in metabolism and electrolyte balance may affect the heart leading to uraemic pericarditis ${ }^{1-11}$ and, perhaps, to uraemic cardio-

Received for publication 23 December 1980 myopathy. ${ }^{11213}$ Hence an entirely normal heart in chronic renal failure is an exception rather than the rule, and the diseased heart is quite easily affected by the haemodynamic alterations caused by haemodialysis.

Several reports have been published concerning echocardiographic demonstration of cardiac changes in chronic renal failure $5101114-17$ and of the cardiac effects of haemodialysis as disclosed by several methods, ${ }^{18-24}$ but the results have been to some extent variable because of methodological differences and unequal patient groups, often including both hypertensive and normotensive patients. Because the hypertensive patients may have more advanced disease and are usually under antihypertensive drug treatment, they might be 
particularly prone to the possible adverse effects of haemodialysis.

The purpose of the present study was to investigate by echocardiography, (1) the kinds of cardiac changes found in patients with chronic renal failure and uraemia, (2) which of these changes are the result of arterial hypertension, and (3) how haemodialysis influences these changes in patients with and without hypertension.

\section{Patients and methods}

Forty-one patients, seen consecutively, 11 women and 30 men, all with chronic renal failure and uraemia treated with maintenance haemodialysis, were investigated before and after a total of 69 haemodialyses. The age of the patients ranged from 18 to 63 years, mean age 38 years. Thirty-one of the patients were hypertensive, seven women and 24 men, and 10 were normotensive, four women and six men. The causes of the chronic renal failure in both patient groups are presented in Table 1 . The antihypertensive treatment of hypertensive patients usually consisted of a diuretic, beta-blocking, and vasodilatating drugs. All the patients had an arteriovenous fistula in either upper extremity, constructed by the same surgeon. None of the patients had a history of myocardial infarction or evidence of coronary artery disease. All the patients were treated with haemodialysis lasting four hours three times weekly.

The echocardiographic examinations were made immediately before and within 30 minutes of completion of haemodialysis. Echocardiograms were obtained with an ATL Mark III real-time echocardiographic system using a mechanical sector transducer with a $90^{\circ}$ angle and frequency of 3.0 megaHertz. The M-mode echocardiogram, electrocardiogram, and carotid pulse tracing were recorded with a Honeywell fibreoptic recorder equipped with a black and white adapter using 3M-Dry Silver paper and $50 \mathrm{~mm} / \mathrm{s}$ paper speed. In the initial studies a Picker Echoview ultrasonoscope equipped with a Polaroid film recorder was used. Echocardiograms were recorded by the same echocardiographer (MI) using an accurate standard technique ${ }^{25}$ routinely employed in this laboratory. ${ }^{26}$

The left ventricular end-diastolic diameter(LVDd) and wall thicknesses were measured at the point of the $\mathbf{R}$ wave in the electrocardiogram. The left ventricular volumes were calculated using the prolate ellipse formula, and the cardiac output was calculated as the product of the left ventricular stroke volume and the heart rate. The fractional shortening of the left ventricular minor axis diameter in systole (FS) was calculated as (LVDd-LVDs)/ LVDd $\times 100$, where LVDd and LVDs are left ventricular end-diastolic and end-systolic diameters, respectively. The mean velocity of the left ventricular circumferential muscle fibre shortening (mVCF) was calculated as previously described, ${ }^{27}$ using in the calculation the left ventricular ejection time measured from the simultaneously recorded carotid pulse tracing. The left ventricular mass was determined by using LVDd and the mean value of the left ventricular posterior wall and the interventricular septal thicknesses according to the formula previously established. ${ }^{28}$ Student's $t$ test was used in analysing the differences between various groups and the paired $t$ test was used in analysing the differences between the results of serial studies of the same patient group. Two variable linear regression estimates were used in correlation studies.

\section{Results}

DIFFERENCES IN MEASUREMENTS BETWEEN HYPERTENSIVE AND NORMOTENSIVE

PATIENTS BEFORE HAEMODIALYSIS (Table 2) Hypertensive and normotensive patient groups did not differ significantly in regard to the mean age, body weight, and skin surface area. The mean time from the beginning of the maintenance haemodialysis treatment and the mean time from the construction of the arteriovenous fistula also did not differ between the patient groups. There were no significant differences in the mean predialysis values of blood haemoglobin, serum potassium, and urea concentrations. Neither were there significant differences between the groups in the heart rate, left ventricular ejection time, LVDd, FS, $\mathrm{mVCF}$, or in the cardiac index.

The systolic and diastolic blood pressures in hypertensive patients were higher than in the normotensive group $(p<0.001)$. Concerning echocardiographic measurements, the left atrial diameter (LAD) $(p<0.001)$, the left ventricular posterior wall

Table 1 Causes of chronic renal failure

\begin{tabular}{|c|c|c|c|c|c|c|c|c|}
\hline & $\begin{array}{l}\text { Glomerulo- } \\
\text { nephritis }\end{array}$ & $\begin{array}{l}\text { Interstitial } \\
\text { nephritis }\end{array}$ & $\begin{array}{l}\text { Pyelo- } \\
\text { nephritis }\end{array}$ & $\begin{array}{l}\text { Hydro- } \\
\text { nephrosis }\end{array}$ & $\begin{array}{l}\text { Polycystic } \\
\text { disease }\end{array}$ & $\begin{array}{l}\text { Amyloid } \\
\text { disease }\end{array}$ & Diabetes & Hypertension \\
\hline $\begin{array}{l}\text { Hypertensive patients } \\
\text { Normotensive patients }\end{array}$ & $\begin{array}{r}20 \\
3\end{array}$ & $\begin{array}{l}2 \\
2\end{array}$ & $\frac{-}{2}$ & $\frac{-}{2}$ & $\begin{array}{l}2 \\
1\end{array}$ & 1 & 4 & 2 \\
\hline
\end{tabular}


Table 2 Physical and echocardiographic data

\begin{tabular}{|c|c|c|c|}
\hline & Hypertensive patients & Normotensive patients & $P$ value \\
\hline \multicolumn{4}{|l|}{ Blood pressure $(\mathrm{mmHg})$} \\
\hline Systolic & $173.8 \pm 28 \cdot 6(51)$ & $134 \cdot 8 \pm 17 \cdot 3(18)$ & 0.001 \\
\hline Diastolic & $100 \cdot 7 \pm 16 \cdot 3(51)$ & $78.4 \pm 10 \cdot 6(18)$ & 0.001 \\
\hline $\operatorname{LVET}(\mathrm{ms})$ & $289 \pm 28 \quad(51)$ & $296 \quad \pm 32 \quad(18)$ & NS \\
\hline Left atrial diameter $(\mathrm{mm})$ & $41.7 \pm 6.3(51)$ & $35 \cdot 8 \pm 4 \cdot 2(18)$ & 0.001 \\
\hline LV end-diastolic diameter (mm) & $57.4 \pm 7.6(51)$ & $55.0 \pm 6.2(18)$ & NS \\
\hline Fractional shortening of $\mathrm{LV}$ minor axis (\%) & $27.9 \pm 6.1(51)$ & $31 \cdot 2 \pm 7 \cdot 4(18)$ & NS \\
\hline $\mathrm{mVCF}(\mathrm{circ} / \mathrm{s})$ & $0.98 \pm 0.24(51)$ & $1.05 \pm 0.23(18)$ & NS \\
\hline Cardiac index $\left(1 / \min\right.$ per $\left.\mathrm{m}^{2}\right)$ & $5 \cdot 35 \pm 2.01(51)$ & $4.93 \pm 1.15(18)$ & NS \\
\hline LV posterior wall thickness $(\mathrm{mm})$ & $12 \cdot 3 \pm 2 \cdot 1(31)$ & $9.9 \pm 2.2(10)$ & 0.005 \\
\hline $\mathrm{LV}$ mass $\left(\mathrm{g} / \mathrm{m}^{2}\right)$ & $182 \cdot 7 \pm 56 \cdot 7(31)$ & $131 \cdot 3 \pm 40.6(10)$ & 0.02 \\
\hline IV septal to posterior wall ratio & $1 \cdot 21 \pm 0.16(31)$ & $1.08 \pm 0.09(10)$ & 0.001 \\
\hline
\end{tabular}

Mean \pm standard deviation. Number of measurements in parentheses. IV, interventricular; mVCF, mean velocity of the circumferential muscle fibre shortening; LV, left ventricular; LVET, left ventricular ejection time.

thickness $(\mathrm{p}<0.005)$, the left ventricular mass $(\mathrm{p}<0.02)$, and the ratio of interventricular septal to posterior wall thickness $(p<0.02)$ were greater in hypertensive patients than in the normotensive group. In the hypertensive group the ratio of septal to posterior wall thickness was $>1.3$ in nine patients (29\%), being in two of them 1.5 and 1.55 . In all the normotensive patients this ratio was $<1.3$ or normal. In all the patients there was a significant positive correlation between left atrial diameter and the left ventricular posterior wall thickness $(\mathrm{r}=0.410, \mathrm{p}<0.01)$ and the left ventricular mass $(r=0.353, p<0.025)$, but there was no correlation between left atrial diameter and LVDd $(r=0.050)$. The mitral valve slope was greater in normotensive patients than in the hypertensive group $(p<0.025)$.

In six patients $(15 \%$ of all the patients), all of whom were hypertensive, a slight pericardial effusion was found, which was not considered to cause a haemodynamic disturbance. These patients did not differ from the other patients with regard to serum urea and potassium concentrations.

In hypertensive patients LVDd was considered to be pathological ( $>53 \mathrm{~mm}$ ) in 36 of 51 measurements $(71 \%)$ and in the normotensive group in 15 of 18 measurements $(83 \%)$. Fractional shortening was abnormally low ( $<26 \%$ ) in 17 of $51(33 \%)$ in hypertensive patients and in two of $18(11 \%)$ measurements in the normotensive group. The cardiac index was abnormally low $\left(<2.81 / \mathrm{min}\right.$ per $\left.\mathrm{m}^{2}\right)$ in two of $51(4 \%)$ measurements in hypertensive patients but in no measurements of the normotensive group.

\section{EFFECTS OF HAEMODIALYSIS}

\section{All patients (Table 3)}

In the whole patient group haemodialysis did not cause significant changes in systolic blood pressure, the mitral valve slope, fractional shortening, or in cardiac index. The body weight decreased by $1.2 \pm 1.2 \mathrm{~kg}(\mathrm{p}<0.001)$, the diastolic blood pressure decreased by $5.4 \pm 9.7 \mathrm{mmHg}(\mathrm{p}<0.001)$, and the heart rate increased by $2.8 \pm 11.3$ beats $/ \mathrm{min}$ $(\mathrm{p}<0.05)$. LVDd decreased by $2 \cdot 0 \pm 2.6 \mathrm{~mm}$ $(\mathrm{p}<0.001)$ (Fig. 1) and the left atrial diameter decreased by $1.7 \pm 3.7 \mathrm{~mm}(\mathrm{p}<0.001)$ (Fig. 2). In five measurements LVDd increased $>1 \mathrm{~mm}$ (range 2 to $3 \mathrm{~mm}$ ) and in six measurements the atrial diameter increased $>2 \mathrm{~mm}$ (range 3 to $8 \mathrm{~mm}$ ), which seemed to be a real increase, but only in one patient did repeated measurements show the same trend of increase. The left ventricular ejection time decreased

Table 3 Physical and echocardiographic data before and after 69 haemodialyses in all the patients

\begin{tabular}{|c|c|c|c|c|}
\hline & Before haemodialysis & After haemodialysis & Difference & $P$ value \\
\hline Body weight (kg) & $65 \cdot 5 \pm 9 \cdot 5$ & $64 \cdot 3 \pm 9 \cdot 6$ & $1 \cdot 2 \pm 1 \cdot 2$ & 0.001 \\
\hline Heart rate (beats $/ \mathrm{min}$ ) & $75 \cdot 8 \pm 13 \cdot 3$ & $78 \cdot 6 \pm 16 \cdot 1$ & $2 \cdot 8 \pm 11 \cdot 3$ & 0.05 \\
\hline \multicolumn{5}{|l|}{ Blood pressure (mmHg) } \\
\hline Systolic & $163 \cdot 6 \pm 31 \cdot 2$ & $161 \cdot 2 \pm 33 \cdot 7$ & $2 \cdot 4 \pm 21 \cdot 9$ & NS \\
\hline Diastolic & $95 \cdot 1 \pm 17 \cdot 9$ & $89 \cdot 7 \pm 17 \cdot 8$ & $5 \cdot 4 \pm 9 \cdot 7$ & 0.001 \\
\hline LVET $(\mathrm{ms})$ & $291 \pm 29$ & $268 \pm 27$ & $22 \pm 23$ & 0.001 \\
\hline Left atrial diameter $(\mathrm{mm})$ & $40 \cdot 2 \pm 6 \cdot 3$ & $38.5 \pm 6.0$ & $1 \cdot 7 \pm 3.7$ & 0.001 \\
\hline LV end-diastolic diameter ( $\mathrm{mm}$ ) & $56 \cdot 8 \pm 7 \cdot 3$ & $54 \cdot 8 \pm 7 \cdot 2$ & $2 \cdot 0 \pm 2 \cdot 6$ & 0.001 \\
\hline Fractional shortening of LV minor axis (\%) & $28 \cdot 8 \pm 6 \cdot 6$ & $29.0 \pm 7 \cdot 6$ & $0 \cdot 2 \pm 4 \cdot 7$ & NS \\
\hline $\mathrm{mVCF}(\mathrm{circ} / \mathrm{s})$ & $1.00 \pm 0.24$ & $1.09 \pm 0.31$ & $0.09 \pm 0.25$ & 0.001 \\
\hline Cardiac index $\left(1 / \min\right.$ per $\left.\mathrm{m}^{2}\right)$ & $5.24 \pm 1.83$ & $5.00 \pm 2.03$ & $0.24 \pm 1 \cdot 16$ & NS \\
\hline
\end{tabular}

Mean \pm standard deviation. LV, left ventricular; LVET, left ventricular ejection time; mVCF, mean velocity of the circumferential muscle fibre shortening. 


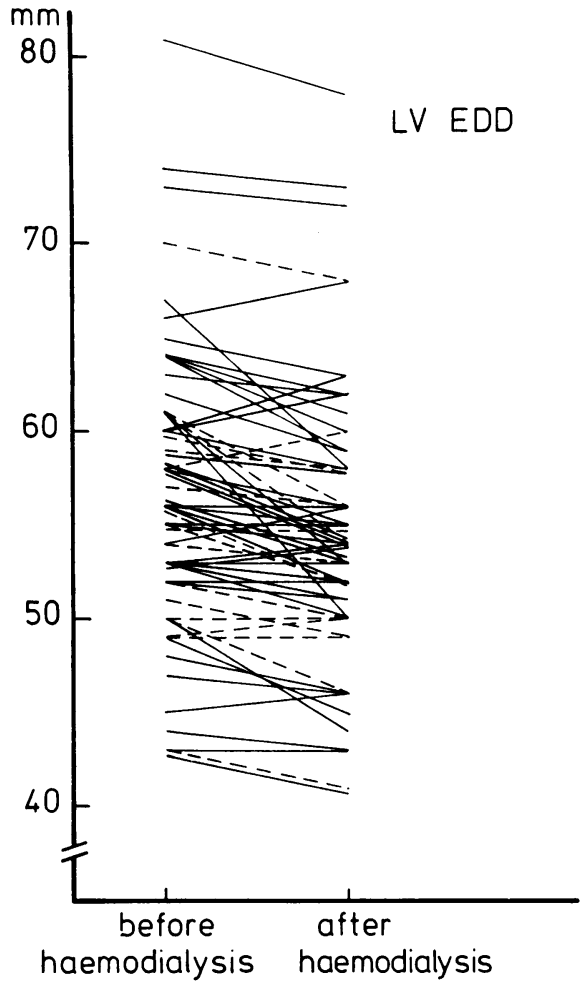

Fig. 1 The changes of left ventricular end-diastolic diameters caused by haemodialysis (mean decrease $2 \cdot 0 \pm 2.6 \mathrm{~mm}$ ). Constant lines = hypertensive patients; broken lines $=$ normotensive patients.

by $22 \pm 23 \mathrm{~ms}(\mathrm{p}<0.001)$ and mVCF increased by $0.09 \pm 0.25 \mathrm{circ} / \mathrm{s}(\mathrm{p}<0.001)$.

The changes of left atrial diameter, LVDd, or the indices of the left ventricular function did not correlate significantly with the changes of the body weight or blood pressure.

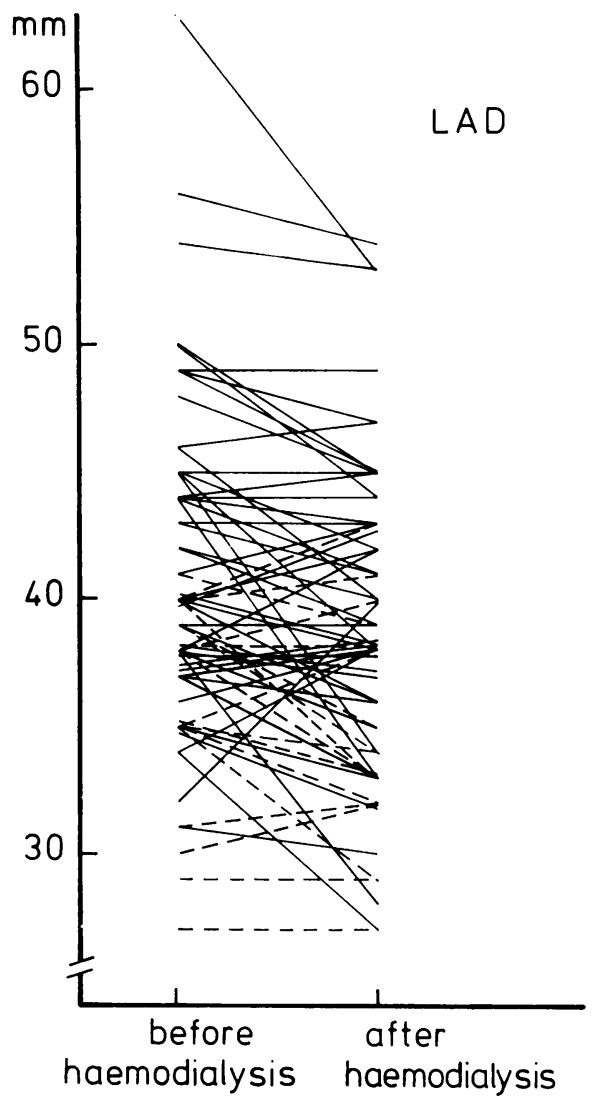

Fig. 2 The changes of left atrial diameters caused by haemodialysis (mean decrease $1 \cdot 7 \pm 3 \cdot 7 \mathrm{~mm}$ ). Constant lines $=$ hypertensive patients; broken lines $=$ normotensive patients.

Differences between hypertensive and normotensive patients (Table 4)

The decrease in the body weight and serum potas-

Table 4 Changes in physical and echocardiographic measurements caused by haemodialysis

\begin{tabular}{|c|c|c|c|c|}
\hline & $\begin{array}{l}\text { Hypertensive patients } \\
n=51\end{array}$ & $P$ value & $\begin{array}{l}\text { Normotensive patients } \\
n=18\end{array}$ & $P$ value \\
\hline $\begin{array}{l}\text { Body weight }(\mathrm{kg}) \\
\text { Heart rate (beats/min) } \\
\text { Blood pressure (mmHg) }\end{array}$ & $\begin{array}{l}-1 \cdot 2 \pm 1.2 \\
+1.9 \pm 11.6\end{array}$ & $\begin{array}{l}0.001 \\
\text { NS }\end{array}$ & $\begin{array}{r}-0.8 \pm 1.1 \\
+5.3 \pm 10.3\end{array}$ & $\begin{array}{l}0.01 \\
0.05\end{array}$ \\
\hline $\begin{array}{l}\text { Systolic } \\
\text { Diastolic } \\
\text { LVET (ms) } \\
\text { Left atrial diameter (mm) } \\
\text { LV end-diastolic diameter (mm) } \\
\text { Fractional shortening of } \mathrm{LV} \text { minor axis }(\%) \\
\text { mVCF (circ/s) } \\
\text { Cardiac index }\left(1 / \mathrm{min} \text { per } \mathrm{m}^{2}\right)\end{array}$ & $\begin{array}{l}-3.4 \pm 24.9 \\
-5.4 \pm 10.1 \\
-21 \quad \pm 24 \\
-1.9 \pm 3.8 \\
-2 \cdot 1 \pm 2.8 \\
-0.2 \pm 4.8 \\
+0.08 \pm 0.21 \\
-0.32 \pm 1.21\end{array}$ & $\begin{array}{l}\text { NS } \\
0.001 \\
0.001 \\
0.001 \\
0.001 \\
\text { NS } \\
0.02 \\
\text { NS }\end{array}$ & $\begin{array}{l}-0.6 \pm 10.1 \\
-5.5 \pm 9.5 \\
-26 \pm 19 \\
-1.2 \pm 3.1 \\
-1.8 \pm 2.2 \\
+1.5 \pm 4.7 \\
+0.16 \pm 0.21 \\
-0.03 \pm 0.98\end{array}$ & $\begin{array}{l}\text { NS } \\
0.05 \\
0.001 \\
\text { NS } \\
0.005 \\
\text { NS } \\
0.01 \\
\text { NS }\end{array}$ \\
\hline
\end{tabular}

$+=$ increase; $-=$ decrease; mean \pm standard deviation; mVCF, mean velocity of the circumferential muscle fibre shortening; LV, left ventricular; LVET, left ventricular ejection time. 
sium concentration caused by haemodialysis did not differ significantly between the hypertensive and normotensive groups, but the serum urea concentration decreased more in normotensive patients $(p<$ $0 \cdot 02$ ). The cardiac changes caused by haemodialysis were similar in both hypertensive and normotensive patients except that left atrial diameter decreased significantly only in hypertensive patients $(p<0.001)$ and the heart rate increased only in normotensive patients $(p<0.05)$.

\section{Discussion}

Hypertensive and normotensive patient groups were similar with regard to age, sex, body weight, and skin surface area, heart rate, duration of haemodialysis treatment, and arteriovenous fistula insertion. Though the possibility of subclinical coronary artery disease is more probable in the patients with hypertension, especially in the four diabetic patients in this study group, the main cause for differences in measurements between the groups seemed to be arterial hypertension. Both systolic and diastolic blood pressures were clearly higher in the hypertensive group.

There may, of course, be errors in the echocardiographic measurements, especially concerning left ventricular measurements in patients with pronounced left ventricular hypertrophy, because the increased trabeculation of the left ventricular wall may impair clear endocardial echoes. This chance of error was minimised by using a strictly standardised technique and the same echocardiographer. The possible coronary artery disease might cause asynergy in systole and thus error in measuring the indices of left ventricular function, but this is less obvious in resting studies, and in sector studies there was no evidence of asymmetric left ventricular contractions.

In chronic renal failure the cardiac output is usually increased because of several factors: increased oxygen demand of the tissues, chronic anaemia, hypervolaemia, and arteriovenous fistula. ${ }^{1-6}$ Though metabolic alterations of acute uraemia may increase cardiac output and contractility, ${ }^{29} 30$ chronic uraemia may possibly lead to congestive cardiomyopathy. ${ }^{13}$ The severity of anaemia and uraemia, however, in the patient groups was similar, and the sizes of the arteriovenous fistulas were probably also similar because they had been made by the same surgeon. The mean LVDd, cardiac index, or the indices of left ventricular function did not differ significantly between the patient groups. Indeed, the mean cardiac index was greater than normal in both groups. The increased cardiac output and volume overload both increase the left ventricular volume and hence in both patient groups the mean LVDd was equally greater than normal.

The mean left ventricular wall thickness and mass were greater in the hypertensive group than in normotensive patients, obviously in response to the increased blood pressure. The mean left atrial diameter was also significantly greater in hypertensive patients, and the left atrial dilatation seemed to depend more on the decreased compliance of the hypertrophied left ventricular wall than on the volume overload, as we have also found in competing athletes. ${ }^{31}$ The difference in the mitral valve slope between hypertensive and normotensive patients also reflects a decreased left ventricular diastolic compliance. In 29 per cent of hypertensive patients the left ventricular hypertrophy was asymmetrical and because in two of the patients the septal to posterior wall ratio was $\geqq 1 \cdot 5$, this can no longer be considered to be a sufficient criterion for idiopathic hypertrophic cardiomyopathy, which is in agreement with previous studies. ${ }^{14} 16$ Though fractional shortening did not differ significantly between the patient groups, in hypertensive patients it was more often depressed, reflecting a more advanced cardiac disease as a response to chronically increased afterload. Hence, the influence of hypertension on the left ventricle may be more deleterious than other effects of chronic renal failure, which emphasises the importance of proper treatment of hypertension in those patients.

\section{EFFECTS OF HAEMODIALYSIS}

Because of fluid loss caused by haemodialysis the body weight decreased, a little more clearly in hypertensive than in normotensive patients. The change in blood volume decreased the left ventricular filling, and thus LVDd decreased similarly in both patient groups. In spite of this the cardiac index decreased only insignificantly. In previous reports the cardiac output was found to be decreased ${ }^{19}$ or increased $^{21}$ during haemodialysis but either decreased ${ }^{219}$ or unchanged 172024 after it. In those reports where cardiac output decreased, the mean decrease of the body weight and thus volume loss was remarkably greater than in the present study. ${ }^{2} 19$ Because of the lack of correlation between the changes of body weight and the changes of LVDd or cardiac index, the changes of cardiac output seem to depend on several factors and not only on decreased filling pressure. In the present study the slight decrease of arterial pressure and increase of the heart rate may also lessen the decrease of cardiac index. A slight increase of LVDd found in some measurements seemed accidental rather than a clearly different haemodynamic reaction. Haemodialysis 
did not cause a change in fractional shortening, as found previously. ${ }^{2}{ }^{17} \mathrm{Hung}$ et al., ${ }^{19}$ however, found a significant rise of ejection fraction in patients with a depressed left ventricular function. We did not find such a phenomenon in those patients with low fractional shortening, but such patients were, however, more often hypertensive, so that it might partially be a result of antihypertensive medication, especially beta-blocking treatment. On the contrary, $\mathrm{mVCF}$ increased principally because of a significant decrease of the left ventricular ejection time. The left ventricular ejection time has been found to be shortened after haemodialysis, perhaps because of left ventricular dysfunction ${ }^{22}$ or reduced stroke volume because of decreased left ventricular filling. ${ }^{32}$ In the present study the increase of $\mathrm{mVCF}$ may also reflect increased left ventricular contractility obviously because of changes in metabolic and electrolyte balance. ${ }^{12}$

The differences in cardiac effects of haemodialysis between hypertensive and normotensive patients were very small. The heart rate did not increase in hypertensive patients perhaps because of beta-blocking treatment. Left atrial diameter decreased significantly only in the hypertensive group, perhaps because of a greater number of measurements, but it may also reflect more sensitivity of the hypertrophied left ventricle to the changes of blood volume. In general, hypertensive and normotensive patients seem to be equally prone to the haemodynamic effects of haemodialysis.

Financial support for this study was granted by Ida Montin's Foundation.

\section{References}

1 Scharf S, Wexler J, Longnecker RE, Blaufox MD. Cardiovascular disease in patients on chronic hemodialytic therapy. Prog Cardiovasc Dis 1980; 22: 343-56.

2 Riley SM Jr, Blackstone EH, Sterling WA, Diethelm AG. Echocardiographic assessment of cardiac performance in patients with arteriovenous fistulas. Surg Gynecol Obstet 1978; 146: 203-8.

3 Saha SP, Roman J, Zaidi SA. Hemodynamic effects of arteriovenous fistula and bovine graft fistula used for hemodialysis. Am Surg 1978; 44: 742-3.

4 Bergrem H, Flatmark A, Simonsen S. Dialysis fistulas and cardiac failure. Acta Med Scand 1978; 204: 191-3.

5 von Bibra H, Castro L, Autenrieth G, McLeod A, Gurland HJ. The effects of arteriovenous shunts on cardiac function in renal dialysis patients-an echocardiographic evaluation. Clin Nephrol 1978; 9: 2059.

6 Lazarus JM, Lowrie EG, Hampers CL, Merrill JP. Cardiovascular disease in uremic patients on hemo- dialysis. Kidney Int 1975; 7, suppl 2: 167-75.

7 Silverberg S, Oreopoulos DG, Wise DJ, et al. Pericarditis in patients undergoing long-term hemodialysis and peritoneal dialysis. Incidence, complications and management. $\mathrm{Am}$ f Med 1977; 63: 874-80.

8 Mitchell AG. Pericarditis during chronic haemodialysis therapy. Postgrad Med F 1974; 50: 741-5.

9 Tarján J, Gofman L, Boros GY, et al. Haemorrhagic pericarditis and cardiac tamponade during chronic haemodialysis. Int Urol Nephrol 1976; 8: 79-85.

10 Goldstein DH, Nagar C, Srivastava N, Schacht RA, Zerris FZ, Flowers NC. Clinically silent pericardial effusions in patients on long-term hemodialysis. Chest 1977; 72: 744-7.

11 Connors JP, Kleiger RE, Shaw RC, et al. The indications for pericardiectomy in the uremic pericardial effusion. Surgery 1976; 80: 689-94.

12 Penpargkul S, Kuziak J, Scheuer J. Effect of uremia upon carbohydrate metabolism in isolated perfused rat heart. $f$ Mol Cell Cardiol 1975; 7: 499-511.

13 Drüeke T, Le Pailleur C, Meilhac B, et al. Congestive cardiomyopathy in uraemic patients on long term haemodialysis. $\mathrm{Br} \mathrm{Med} \mathrm{F} \mathrm{1977;} \mathrm{i:} \mathrm{350-3.}$

14 Schott CR, Kotler MN, Segal BL, Parry W, Mahan J. Echocardiographic spectrum in chronic renal failure (abstract). Circulation 1976; 54, suppl 2: 221.

15 D'Cruz IA, Bhatt GR, Cohen HC, Glick G. Echocardiographic detection of cardiac involvement in patients with chronic renal failure. Arch Intern Med 1978; 138: 720-4.

16 Abbasi AS, Slaughter JC, Allen MW. Asymmetric septal hypertrophy in patients on long-term hemodialysis. Chest 1978; 74: 548-51.

17 Cohen MV, Diaz P, Scheuer J. Echocardiographic assessment of left ventricular function in patients with chronic uremia. Clin Nephrol 1979; 12: 156-62.

18 Goss JE, Alfrey AC, Vogel JHK, Holmes JH. Hemodynamic changes during hemodialysis. Trans Am Soc Artif Intern Organs 1967; 13: 68-76.

19 Hung J, Harris PJ, Uren RF, Tiller DJ, Kelly DT. Uremic cardiomyopathy-effect of hemodialysis on left ventricular function in end-stage renal failure. $N$ Engl f Med 1980; 302: 547-51.

20 del Greco F, Simon NM, Roguska J, Walker C. Hemodynamic studies in chronic uremia. Circulation 1969; 40: 87-95.

21 Endou K, Kamijima J, Kakubari Y, Kikawada R. Hemodynamic changes during hemodialysis. Cardio$\log y$ 1978; 63: 175-87.

22 Mahajan S, Kinhal V, Gardiner H, Briggs W, McDonald F. Cardiac functional changes during hemodialysis. Proc Clin Dial Transplant Forum 1977; 7: 99-103.

23 Henderson LW, Ambrosi C, Starr I. Cardiodynamic studies of uremics before and after dialysis. Nephron 1971; 8: 511-27.

24 Strangfeld D, Günther KH, Bohm R, Günther H, Buchali K, Dutz $H$. Cardiac function in chronic renal failure before and after hemodialysis. Cardiology 1973; 58: 109-17.

25 Feigenbaum H. Echocardiography. 1st ed. Phila- 
delphia: Lea \& Febiger, 1972; 37-9.

26 Ikäheimo $M$, Takkunen J. Echocardiography in assessment of mitral valve disease II. Left atrium and left ventricle. Ann Clin Res 1977; 9: 321-9.

27 Cooper RH, O'Rourke RA, Karliner JS, Peterson KL, Leopold GR. Comparison of ultrasound and cineangiographic measurements of the mean rate of circumferential fiber shortening in man. Circulation 1972; 46: 914-23.

28 Troy BL, Pombo J, Rackley CE. Measurement of left ventricular wall thickness and mass by echocardiography. Circulation 1972; 45: 602-11.

29 Penpargkul S, Scheuer J. Effect of uraemia upon the performance of the rat heart. Cardiovasc Res 1972; 6: $702-8$.

30 Knowlan DM, Piatnek DA, Olson RE. Myocardial metabolism and cardiac output in acute uremia (abstract). Clin Res 1961; 9: 141.

31 Ikäheimo MJ, Palatsi IJ, Takkunen JT. Noninvasive evaluation of the athletic heart: sprinters versus endurance runners. Am $\mathcal{F}$ Cardiol 1979; 44: 24-30.

32 Bornstein A, Zambrano SS, Morrison RS, Spodick DH. Cardiac effects of hemodialysis: noninvasive monitoring by systolic time intervals. $\mathrm{Am} \mathrm{f} \mathrm{Med} \mathrm{Sci}$ 1975; 269: 189-92.

Requests for reprints to Dr Markku Ikäheimo, Cardiovascular Division, Department of Medicine, Oulu University Central Hospital, SF-90220 Oulu 22, Finland. 